\title{
Atresia Folicular en Ovarios de Prochilodus lineatus
}

\author{
Follicular Atresia in Ovaries of Prochilodus lineatus
}

Flores Quintana, C.; Blanco Cohene, T.; Arbués, R.; Domitrovic, H. \& González, J.

FLORES, Q. C.; BLANCO, C. T.; ARBUÉS, R.; DOMITROVIC, H. \& GONZÁLEZ, J. Atresia folicular en ovarios de Prochilodus lineatus. Int. J. Morphol., 30(4):1301-1308, 2012.

RESUMEN: Durante el período reproductivo, en el ovario de los teleósteos se forman cíclicamente folículos primarios, los que maduran y son liberados en el momento de la ovulación. Sin embargo, algunos de ellos desarrollan un proceso de atresia con degeneración y reabsorción, el que para ser considerado un evento fisiológico debería predominar al final del ciclo reproductivo. Las características morfológicas de ovarios de Prochilodus lineatus fueron analizadas para identificar la presencia de folículos atrésicos como indicadores de posibles modificaciones de su biología reproductiva que afecte la repoblación de la especie. En los ovarios de $P$. lineatus predominaron los cambios morfológicos que se corresponden con la denominada atresia tipo I, y los folículos atrésicos fueron observados en peces con índice gonadosomático bajo que se encontraban al final del ciclo reproductivo. La atresia folicular hallada no pudo vincularse con algún proceso patológico que provoque una disminución de la especie en el ecosistema del río Paraná.

PALABRAS CLAVE: Peces; Gónadas; Histología; Sábalo.

\section{INTRODUCCIÓN}

El sábalo es considerado una especie clave del ecosistema del río Paraná, debido a su régimen iliofago, su biomasa alta y sus hábitos migratorios. Por su abundancia en distintos ambientes, constituye el recurso pesquero más importante del litoral fluvial argentino, y es también un eslabón crucial para ser sostén de la cadena trófica (Espinach Ros \& Fuentes, 2000).

Aunque los peces presentan estrategias reproductivas que los adaptan a condiciones ambientales variables, estas variaciones provocan cambios en algunas de sus características reproductivas. El régimen de lluvias y crecidas constituye la principal fuerza selectiva del ambiente en la modulación de la actividad reproductiva, existiendo elevado sincronismo entre las crecientes y los principales eventos del ciclo biológico (Agostinho \& Julio, 1994). Como otras especies migradoras, el sábalo es particularmente vulnerable a la creciente alteración del ambiente como ser la interrupción de los circuitos utilizados, la regulación de los ríos por la construcción de las represas o los niveles de polución en aumento.

En teleósteos, durante el proceso de desarrollo folicular se forman cíclicamente los folículos, desde primarios hasta su fase de maduración y ovulación. Sin embargo, no todos los folículos ováricos que inician su desarrollo lle- gan a madurar, algunos de ellos inician un proceso de degeneración y reabsorción, formando folículos atrésicos. La atresia es un proceso de degeneración y reabsorción de folículos ováricos que ocurre de manera normal en los ovarios de todos los vertebrados, incluidos los peces. Oocitos atrésicos pueden presentarse tanto en peces de vida silvestre como en los que permanecen en cautiverio (Ball, 1960; Saidapur, 1978; Leonardo et al., 2006) y pueden observarse en todos los estadios del ciclo reproductivo, aunque lo más común es observarlos durante el periodo de post-desove (Miranda et al., 1999; Guraya, 1994). En teleósteos, la atresia puede ser inducida por stress, confinamiento, feromonas, estímulos visuales y táctiles, agentes biocidas, contaminación, radiación, inanición, niveles hormonales inadecuados y cambios en las características del ambiente como luz, temperatura, corrientes de agua (Leino et al., 2005; Nagahama, 1983; Zanuy \& Carrillo, 1987).

Varios autores postulan que en los últimos años se produjo una disminución de las poblaciones silvestres de sábalo (Oldani, 2006a, 2006b). La atresia esta vinculada a los índices de fertilidad ya que reduce el número de folículos que maduran. Los folículos atrésicos son importantes indicadores del impacto ambiental en los ovarios de los peces, sin embargo los mecanismos de la atresia folicular no están completamente entendidos. El aumento de la preocu 
pación en la conservación de las especies nativas genera interés en conocer las características de todas las fases de su biología reproductiva de tal manera que se puedan detectar los cambios que podrían llevar a una posible disminución de las mismas.

En este trabajo se analizan los cambios morfológicos en ovarios de Prochilodus lineatus caracterizando particularmente la presencia de folículos atrésicos durante el ciclo reproductivo.

\section{MATERIAL Y MÉTODO}

Se analizaron 316 muestras de ovarios de Prochilodus lineatus capturados en muestreos mensuales desde julio de 2008 a septiembre de 2011 en dos sitios en el río Paraná. Para ello se utilizó una batería de redes enmalladoras de nylon monofilamento y otras artes de pescas complementarias. Se registró el peso del pez capturado y el peso de las gónadas para determinar la relación gonadosomática calculada con la siguiente fórmula RGS\%= (peso total del ovario en gramos/peso total del pez en gramos) x 100 . Macroscópicamente, considerando el color, transparencia, vascularización, flacidez, visualización de ovocitos y espesor de la cápsula, se determinó el estado de desarrollo ovárico utilizando la clasificación: virginal, inicio de maduración, maduración, desove, post-desove y reposo. Una pequeña porción de la gónada fue fijada en solución de Bouin y posteriormente deshidratada e incluida en parafina. Los cortes histológicos coloreados con Hematoxilina-Eosina, PAS y Mallory se analizaron con microscopia óptica. El tamaño de 50 ovocitos fue determinado en cada uno de los ejemplares clasificados como maduros, desove y posdesove utilizando un sistema analizador de imágenes (Software Image -Pro Plus, versión 4.5 Media Cybernetics, Inc.).

\section{RESULTADOS Y DISCUSIÓN}

Aún cuando la atresia folicular es un fenómeno involutivo normal en los ovarios de todos los vertebrados incluidos los peces, constituyendo uno de los eventos más enigmáticos de la biología reproductiva (Hurwitz \& Adashi, 1992). Los folículos atrésicos de $P$. lineatus predominaron en los meses de febrero a mayo en ejemplares con RGS inferior a $6,5 \%$, y en estadio folicular posvitelogénico. Se señaló que la atresia puede presentarse en cualquier momento del desarrollo oocitario (Ganias et al., 2008 ; Leonardo et al.; Miranda et al.), sin embargo en cautividad, lo más común es que aparezca en las fases de vitelogénesis y preovulatoria (Bromage \& Cumaranatunga, 1988; LinaresCasenave et al., 2002; Miranda et al.). En algunas especies, los factores más importantes que determinan el destino hacia la ovulación o la atresia de los folículos son la capacidad de respuesta a gonadotropinas, la capacidad de producir estradiol (Bao \& Garverick, 1998; Braw-Tal \& Roth, 2005; Garverick et al., 2002; Webb et al., 1999), la participación del sistema de factor de crecimiento insulinoide (IGF) (Rivera \& Fortune, 2003a, 2003b) y el medio endocrinológico en el que se desarrollan (Webb et al.).

Los folículos atrésicos de $P$. lineatus compartieron un patrón común a nivel estructural. Se encontró disminución progresiva del diámetro folicular, fragmentación del corion y disolución del contenido citoplasmático (Fig. 1AB), observándose como un proceso degenerativo paulatino e irreversible, que se extiende a todo el folículo, lo que determina la pérdida de su integridad y por lo tanto de su funcionalidad (Chedrese, 2003; Sharma, 2000).

En algunas especies la incidencia de atresia fue directamente relacionada con el tamaño de los folículos así, donde en los folículos más grandes, por presentar un índice proliferativo mayor, se tornan más susceptibles a la muerte por apoptosis y por lo tanto a la atresia (Rosales Torres \& Guzmán Sánchez, 2008). En P. lineatus los folículos maduros tuvieron un diámetro medio de $698,45 \mu$, en tanto que en los folículos atrésicos detectados en el inicio del proceso era de $565 \mu$.

El primer signo de atresia descripto a nivel microscópico es la desintegración del núcleo del oocito seguido de la fragmentación de la zona pelúcida (Lowerre-Barbieri et al., 1996; Mylonas et al., 1997). El primer evento observado en el sábalo fue la presencia de ondulaciones del corion (Fig. 1 C-F), que coincide con la fase alfa descripta en Chaetodon multicinctus (Tricas \& Hiramoto, 1989).

Los gránulos de vitelo perdieron su individualidad (Fig. $1 \mathrm{G}-\mathrm{H}$ ) y las células de la granulosa se hipertrofiaron. Estas modificaciones fueron descriptas por algunos autores que además observaron hipertrofia de células tecales (Linares-Casenave et al.; Nagahama). En P. lineatus no se observaron células tecales hipertróficas, lo que coincide con el escaso desarrollo celular descripto en L. taeniatus (Santos et al., 2008).

La caracterización del proceso de atresia realizada por diferentes autores, en especies diferentes y con distintos criterios, explica la falta de unificación de la nomenclatura (Khoo, 1975; Rutaisire \& Booth, 2004; Santos et al.). Algunos autores describen las etapas de la atresia folicular en base a los datos morfológicos (Bretschneider \& Duyvene 


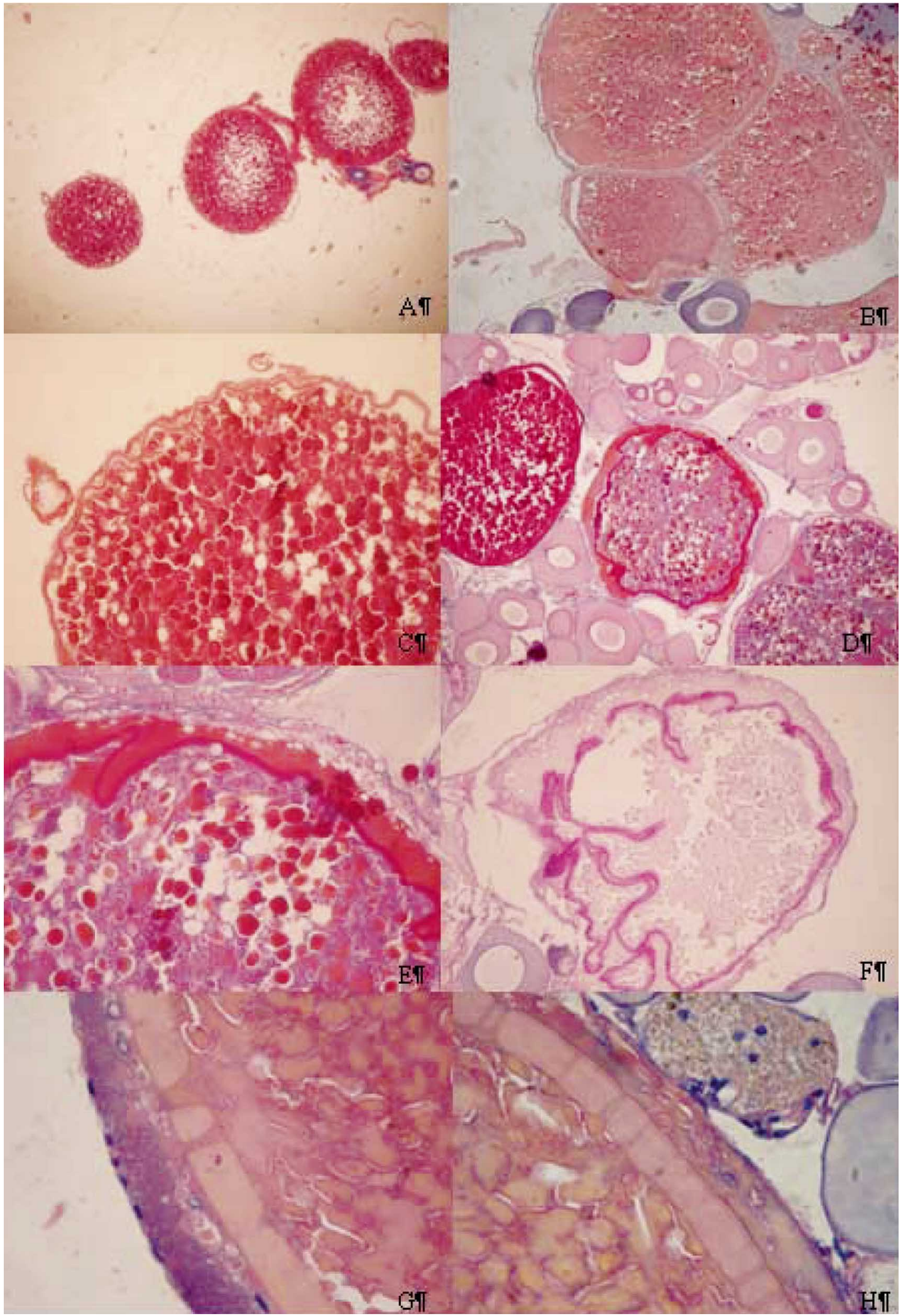

Fig. 1. Ovario de Prochilodus lineatus, folículo atrésico A-B: Disminución progresiva del diámetro folicular. C-DE-F: ondulaciones del corion $\mathrm{G}$ y $\mathrm{H}$ : fragmentación del corion y pérdida de individualidad de los gránulos de vitelo. A-B-C-G-H: HE; D-E: Mallory; F: PAS. A: 4X, B-D:10X, C-F: 20X, E:40X, G-H: 100X. 


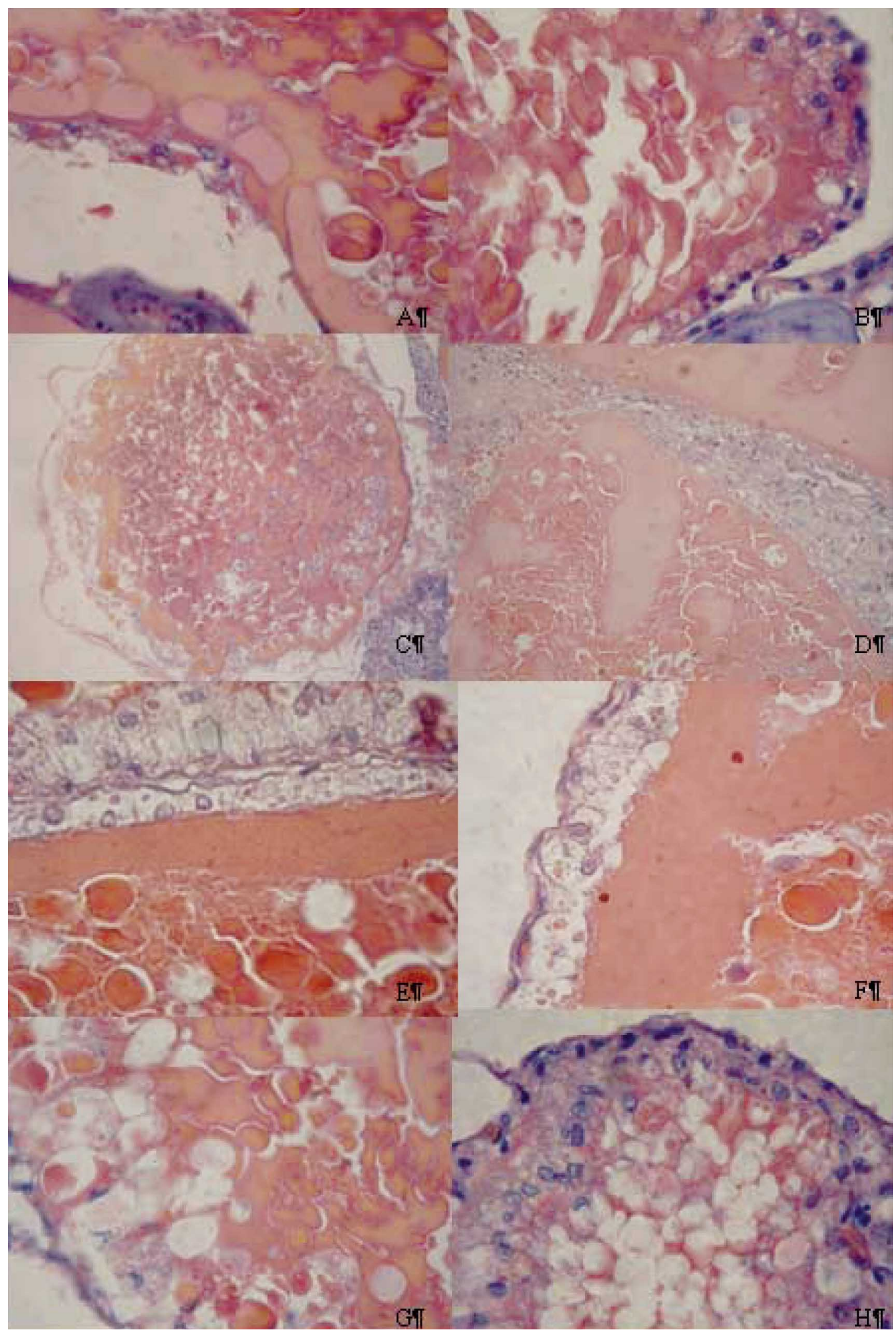

Figura 2: Ovario de Prochilodus lineatus, folículo atresico A-D: Disolución del contenido de gránulos. E-H: Hipertrofia de células de la granulosa y migración hacia el interior del folículo. HE. A-B: 100X, C: 20X, D: 40X, E-H: 100X. 
de Wit, 1947), mientras que otros separan los folículos atrésicos en hipertróficos y no hipertróficos (Uribe Aranzábal et al., 2006).

En P. lineatus se observa que las células de la granulosa hipertrofiadas se desplazan, migran y fagocitan el vitelo (Fig. 2A-H). La presencia de grandes vacuolas digestivas en el citoplasma de las células de la granulosa, obtenidas por heterofagia, coincide con lo descripto en $P$. argenteus (Santos et al.). En Chaetodon multicinctus se observó que en esta fase las plaquetas de vitelo desaparecen, aunque los lípidos e inclusiones de pigmentos permanecen por un tiempo prolongado (Tricas \& Hiramoto). La actividad fagocítica que se atribuye a las células de la granulosa es solo en el inicio del proceso atrésico (Linares-Casenave et al.).

En P. lineatus los elementos constitutivos del folículo, teca, células foliculares, corion y oocito, fueron desapareciendo gradualmente. Los cambios vasculares a nivel de la teca que fueron observados en algunas especies (Linares-
Casenave et al.; Santos et al.) resultaron prácticamente imperceptibles (Fig. 3A-D), sin embargo se observó escasa infiltración linfoplasmocitaria periférica, indicando una relación con el sistema inmune, detalle observado en otros vertebrados (Santos et al.).

La última etapa del proceso de atresia se caracteriza por la presencia de componentes residuales luego de la reabsorción de vitelo y citoplasma. Algunos trabajos expresan que la duración del proceso de atresia es más reducida en especies que en forma similar al sábalo tienen estrategia reproductiva de puesta total (Miranda et al.). Los cuerpos atrésicos multicelulares fueron encontrados en las distintas muestras de $P$. lineatus durante los sucesivos muestreos (Fig. 4A), observándose que los cuerpos formados en esta etapa persisten en el ovario por muchos meses. Por sus características morfológicas fueron relacionados inicialmente con la biosíntesis de esteroides (Hoar, 1969), aunque otros trabajos no hallaron evidencias de la secreción hormonal (Leonardo et al.; Linares-Casenave et al.).

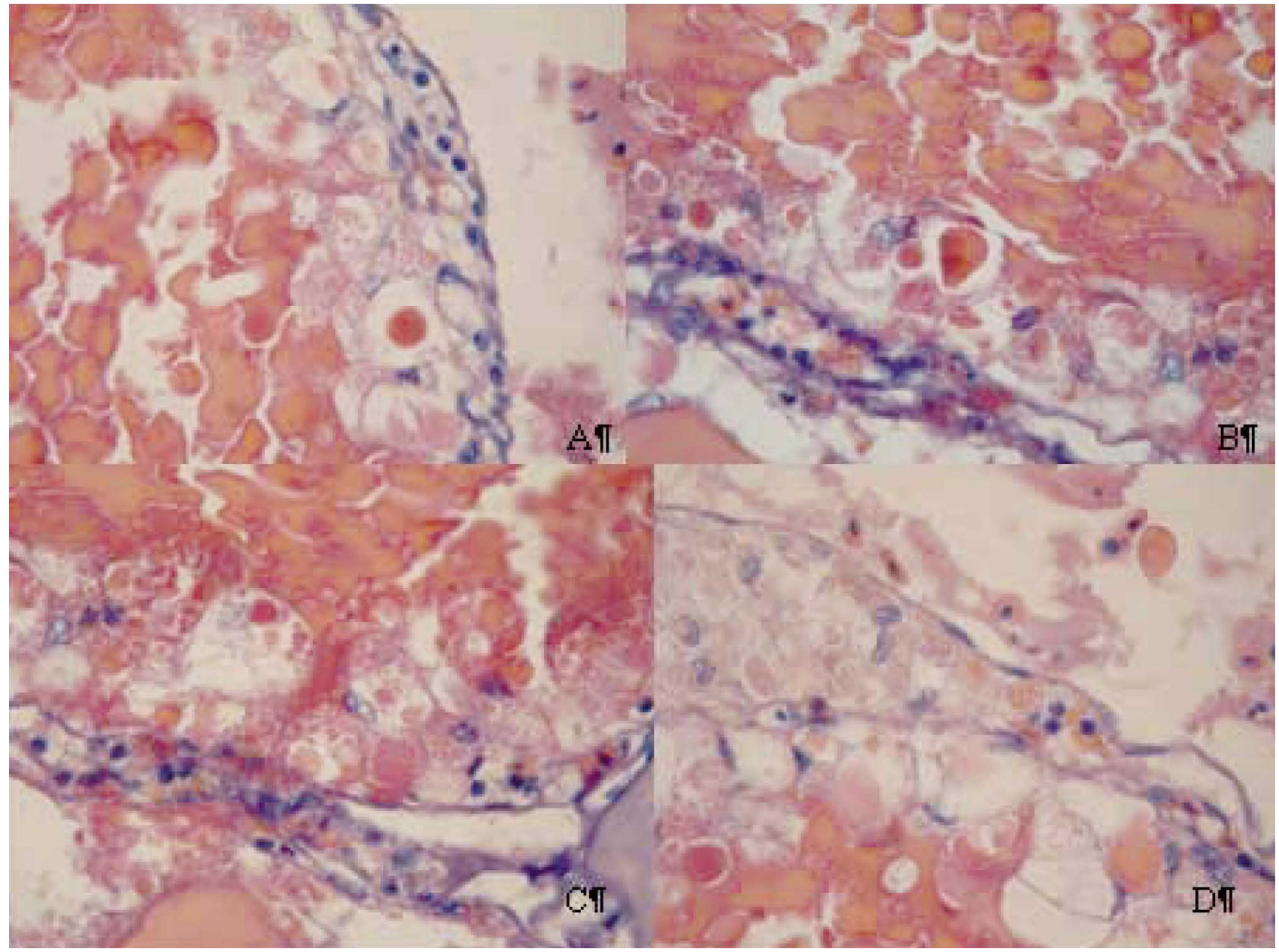

Fig. 3. Ovario de Prochilodus lineatus, folículo atrésico. A-D: Vacuolas digestivas en el citoplasma de las células de la granulosa Escasas modificaciones vasculares, ligera infiltración de linfocitos y presencia de células pigmentarias HE, 100X. 
Como en otras especies, en P. lineatus se observan gránulos oscuros dentro y fuera del citoplasma de las células foliculares. Algunos autores identificaron el origen del pigmento oscuro contenido en los folículos atrésicos como lipofucsina, residuo del proceso de digestión del vitelo, corion y orgánulos. Fue señalado que, mediante la atresia, la remoción de los ovocitos que no alcanzaron su desarrollo permite recuperar parte de la energía y los componentes invertidos durante la maduración folicular (Blazer, 2002; Miranda et al.; Norris, 1997; Saidapur ).

La estructura de los folículos atrésicos muestra reducción gradual del tamaño. Al parecer las células tecales están involucradas en los principales cambios fibróticos del folículo, los que resultan en la formación de una densa cápsula alrededor del cuerpo atrésico (Rutaisire \& Booth). La reducción en el tamaño se relaciona con un proceso de apoptosis de las células transformadas de la granulosa, lo que provoca una disminución en el número de células (Linares-Casenave et al.). La presencia de núcleos picnóticos y cariorrexis en las células de la granulosa y teca de folículos atrésicos (Bao \& Garverick; Saidapur), así como la fragmentación internucleosomal del ADN en estas células, permitieron conocer que la apoptosis es el tipo de muerte preponderante en la atresia (Santos et al.; Sharma) aunque no el único (Nagahama). Algunos autores postularon que en esta etapa las células tecales se podrían diferenciar en nuevas células oogoniales (Khoo).

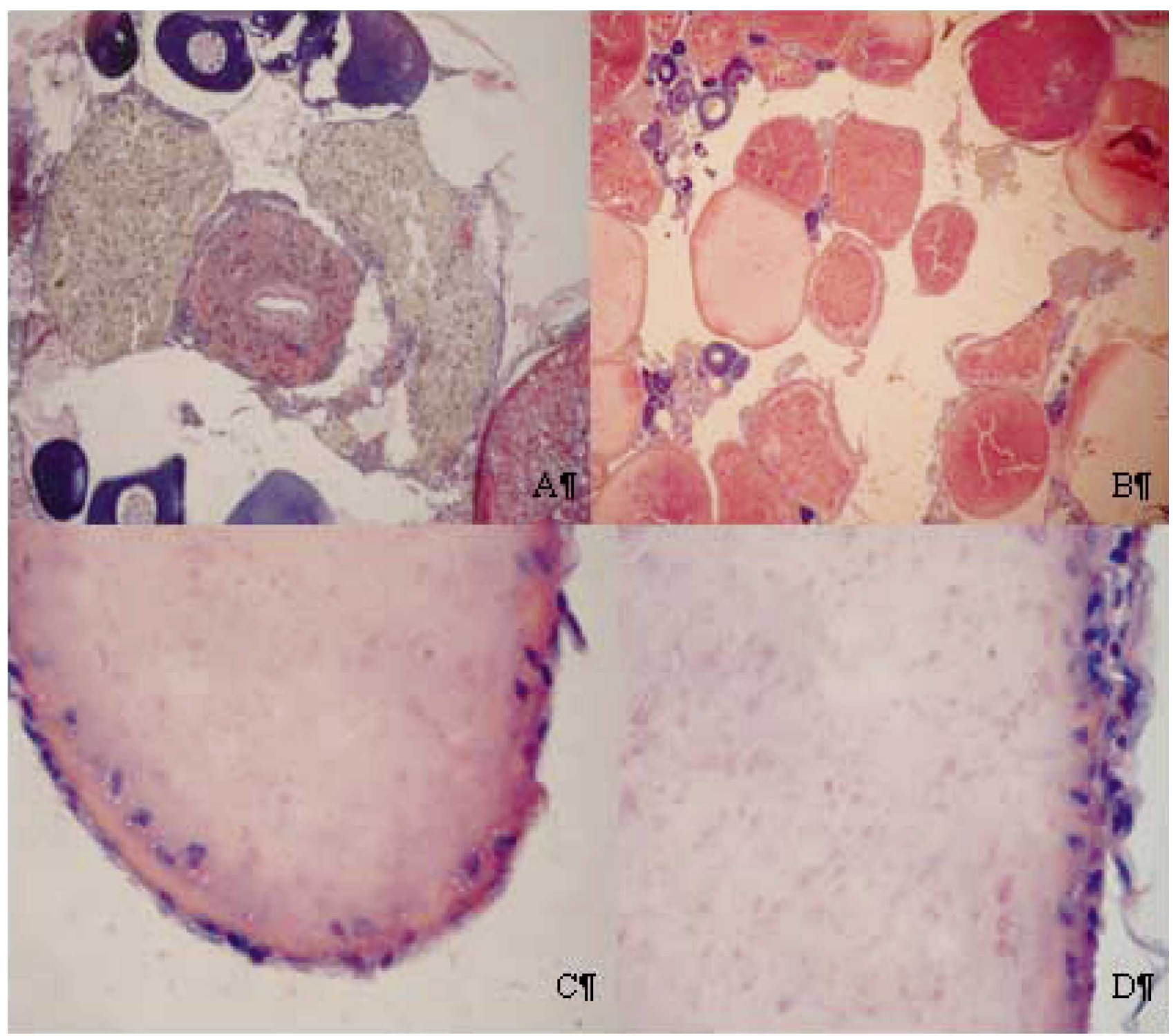

Fig. 4. Ovario de Prochilodus lineatus. A: Cuerpo residual. B-D: Degeneración vacuolar en atresia tipo II, corion conservado sin signos de fagocitosis H-E. A: 20X, B 4X C-D 100X 
La presencia de atresia tipo II, de alta prevalencia encontrada en algunas poblaciones de Labeo victorianus, se caracterizó por el quiebre de los glóbulos vitelinos en gránulos más pequeños, degeneración vacuolar del citoplasma, presencia de corion intacto, sin detectarse signos de fagocitosis. Este es el tipo de atresia relacionada con una falla o interrupción en el desove (Rutaisire \& Booth). Este cambio no fue observado como un evento definido en las gónadas de $P$. lineatus capturados, aunque si pudieron encontrarse escasos folículos atravesando este proceso. (Fig. 4B-D).

\section{CONCLUSIONES}

Dado que los folículos atrésicos pueden ser utilizados como importantes indicadores del impacto ambiental en los ovarios de los peces, en este trabajo las características morfológicas de los folículos atrésicos de $\mathrm{P}$. lineatus se correspondieron con un proceso degenerativo que tuvo su mayor frecuencia en las gónadas de ejemplares en el final del ciclo reproductivo, con RGS baja. Tampoco se pueden establecer vínculos entre la atresia observada en $P$. lineatus con algún proceso patológico que conduzca a la disminución de la especie en el ecosistema del Paraná.

FLORES, Q. C.; BLANCO, C. T.; ARBUÉS, R.; DOMITROVIC, H. \& GONZÁLEZ, J. Follicular atresia in ovaries of Prochilodus lineatus. Int. J. Morphol., 30(4):1301-1308, 2012.

SUMMARY: During the reproductive period, primary follicles are formed cyclically in the ovary of teleost, which mature and are released at the ovulation time. However, some of them develop a process of atresia with degeneration and resorption, which to be considered a physiological event should prevail at the end of the reproductive cycle. Morphological characteristics of ovaries of Prochilodus lineatus were analyzed for the presence of atresic follicles as indicators of possible changes in their reproductive biology affecting the repopulation of the species. In the ovaries of $P$. lineatus dominated the morphological changes that correspond to the so-called type I atresia, and atresic follicles were observed in fish with low gonadosomatic index who were at the end of the reproductive cycle. Detected follicular atresia could not be linked to a pathological process that causes a decline of the species in the Paraná river ecosystem.

KEY WORDS: Fish; Gonad; Histology; Sabalo.

\section{REFERENCIAS BIBLIOGRÁFICAS}

Agostinho, A. \& Julio, H. Peixes da bacia do Alto río Paraná. In: Simposio Internacional sobre Aspectos Ambientais da Bacia do Prata. Río de Janeiro, Instituto ACQUA, 1994. pp.165-86.

Ball, J. Reproduction in female bony fishes. Symp. Zool. Soc. (Lond.), 1:105-35, 1960.

Bao, B. \& Garverick, H. Expression of steroidogenic enzymes and gonadotrophin receptor genes in bovine follicles during ovarian follicular waves: a review. J. Anim. Sci., 76(7):1903-21, 1998.

Blazer, V. Histopathological assessment of gonadal tissues in wild fishes. Fish Physiol. Biochem., 26(1):85-101, 2002.

Braw-Tal, R. \& Roth, Z. Gene expression for LH receptor, 17 alphahydroxilase and StAR in the theca interna of preantral and early antral follicles in the bovine ovary. Reproduction, 129(4):453-61, 2005.

Bretschneider, L. H. \& Duyvene, J. J. Sexual endocrinology of nonmammalian vertebrates. Monographs on the progress of research in Holland during the war. Amsterdam, Netherlands, Elsevier, 1947. Vol. II.

Bromage, N. \& Cumaranatunga, R. Egg production in the rainbow trout. In: Muir, J. F. \& Roberts, R. J. (Eds.). Recent advances in aquaculture. Oxford, UK, Blackwell Scientific Publications, 1988. pp.64-138
Chedrese, J. Regulación autócrina y parácrina del desarrollo folicular I: Efectos de los esteroides. Rev. Col. Cienc. Pec., 16(2):171-82, 2003.

Espinach Ros, A. \& Fuentes, C. Recursos Pesqueros y Pesquerías de la Cuenca del Plata. En: Bezzi, S.; Akselman, R. \& Boschi, E. (Eds.). Síntesis del Estado de las Pesquerías Marítimas Argentinas y de la Cuenca del Plata. Argentina, Instituto Nacional de Investigación y Desarrollo Pesquero, 2000. pp.353-88.

Ganias, K.; Nunes, C. \& Stratoudakis, Y. Use of late ovarian atresia in describing spawning history of sardine, Sardina pilchardus. J. Sea Res., 60(4):297-302, 2008.

Garverick, H.; Baxter, G.; Gong, J.; Armstrong, D. G.; Campbell, B. K.; Gutierrez, C. \& Webb, R. Regulation of expression ovarian mRNA encoding steroidogenic enzymes and gonadotrophin receptors by FSH and GH in hypogonadotrophic cattle. Reproduction, 123(5):651-61, 2002.

Guraya, S. S. Gonadal development and production of gametes in fish. Proc. Indian Nat. Sci Acad., B60(1):15-32, 1994.

Hoar, W. Reproduction. In: Hoar, W. S. \& Randall, D. J. (Eds.). Fish Physiology. New York, Academic Press, 1969. pp.1-72. Vol. III.

Hurwitz, A. \& Adashi, E. Y. Ovarian folicular atresia as an apoptotic process: a paradigm for programmed cell death in endocrine tissues. Mol. Cell Endocrinol., 84(1-2):C19-23, 1992. 
Khoo, K. H. The corpus luteum of goldfish (Carassius auratus) and its functions. Can. J. Zool., 53(9):1306-23, 1975.

Leino, R. L.; Jensen, K. M. \& Ankley, G. Gonadal histology and characteristic histopathology associated with endocrine disruption in the adult fathead minnow (Pimephales promelas). Environ. Toxicol. Pharmacol., 19(1):85-98, 2005.

Leonardo, A. F. G.; Romagosa, E.; Batlouni, S. R. \& Borella, M. I. Occurrence and significance of ovarian and follicular regression in cachara Pseudoplatystoma fasciatum (Linnaeus, 1766): a histology approach. Arq. Bras. Med. Vet. Zootec., 58(5):831-40, 2006.

Linares-Casenave, J.; Van Eenennaam, J. P. \& Doroshov, S. I. Ultrastructural and histological observations on temperatureinduced follicular ovarian atresia in the white sturgeon. J. Appl. Ichthyol., 18(4-6):382-90, 2002.

Lowerre-Barbieri, S. K.; Chittenden, M. E. Jr. \& Barbieri, L. R. The multiple spawning pattern of weakfish in the Chesapeake Bay and Middle Atlantic Bight. J. Fish Biol., 48(6):1139-63, 1996.

Miranda, A. C.; Bazzoli, N.; Rizzo, E. \& Sato, Y. Ovarian follicular atresia in two teleost species: a histological and ultrastructural study. Tissue Cell, 31(5):480-8, 1999.

Mylonas, C. C.; Woods III, L. C. \& Zohar, Y. Cyto-histological examination post vitellogenesis and final oocyte maduration in captive-reared striped bass. J. Fish Biol., 50(1):34-49, 1997.

Nagahama, Y. The functional morphology of teleost gonads. In: Hoar, W. S.; Randall, D. J. \& Donaldson, E. M. (Eds.). Fish Physiology. New York, Academic Press, 1983. pp.223-75. Vol. IX.

Norris, D. Reproduction in bony fishes. Vertebrate Endocrinology. 3rd ed. New York, Academic Press, 1997. pp.425-6.

Oldani, N. Sábalos: un experto reclama prohibir las exportaciones. 2006a. Disponible en: www.produccion-animal.com.ar/ p roduccion _ peces/pis cicultura/2 7 crisis_pesquera_en_el_parana.pdf

Oldani, N. Criterios para la conservación de los sábalos del río Paraná. 2006b. Disponible en: www.sosrioparana.com.ar/notas/Cirteriossabalos.pdf

Rivera, G. M. \& Fortune, J. E. Selection of the dominant follicle and insulin like growth factor (IGF) binding proteins: evidence that pregnancy associated plasma protein A contributes to proteolysis of IGF binding protein 5 in bovine follicular fluid. Endocrinology, 144(2):437-46, $2003 \mathrm{a}$.

Rivera, G. M. \& Fortune, J. E. Proteolysis of insulin-like growth factor binding proteins -4 and -5 in bovine follicular fluid: implications for ovarian follicular selection and dominance. Endocrinology, 144(7):2977-87, 2003b.
Rosales Torres, A. \& Guzmán Sánchez, A. Apoptosis en la atresia folicular y la regresión del cuerpo lúteo. Revisión. Téc. Pecu. Méx., 46(2):159-82, 2008.

Rutaisire, J. \& Booth, A. A histological description of ovarian recrudescence in two Labeo victorianus populations. Afr. J. Aquat. Sci., 29(2):221-8, 2004.

Saidapur, S. K. Follicular atresia in the ovaries of nonmammalian vertebrates. Int. Rev. Cytol., 54:225-44, 1978.

Santos, H. B.; Thomé, R. G.; Arantes, F. P.; Sato, Y.; Bazzoli, N. \& Rizzo, E. Ovarian follicular atresia is mediated by heterophagy, autophagy, and apoptosis in Prochilodus argenteus and Leporinus taeniatus (Teleostei: Characiformes). Theriogenology, 70(9):1449-60, 2008.

Sharma, R. Follicular atresia in goat: A review. Indian J. Anim. Sci., 70(10):1035-46, 2000.

Tricas, T. C. \& Hiramoto, J. T. Sexual differentiation, gonad development, and spawning seasonality of the Hawaiian butterfly fish, Chaetodon multicinctus. Environ. Biol. Fish., 25(1-3):11124, 1989.

Uribe Aranzábal, M. C.; De la Rosa Cruz, G.; García Alarcón, A.; Guerrero-Estévez,, S. M. \& Aguilar Morales, M. Características histológicas de los estadios de atresia de folículos ováricos en dos especies de teleósteos vivíparos: Ilyodon whitei (Meek, 1904) y Goodea atripinnis (Jordan, 1880) (Goodeidae). Hidrobiológica, 16(1):67-73, 2006.

Webb, R.; Campbell, B.; Garverick, H.; Gong, J.; Gutierrez C. \& Armstrong, D. Molecular mechanisms regulating follicular recruitment and selection. J. Reprod. Fertil. Suppl., 54:33-48, 1999.

Zanuy, S. \& Carrillo, M. La reproducción de los peces teleósteos y su aplicación en acuicultura. En: Espinosa de los Monteros, J. \& Labarta, U. (Eds.). Reproducción en acuicultura. Madrid, España, CAICYT, 1987. pp.1-131.

\section{Dirección para Correspondencia: \\ Carolina Flores Quintana \\ Instituto de Ictiología del Nordeste \\ Facultad de Ciencias Veterinarias \\ Universidad Nacional del Nordeste \\ Sargento Cabral 2139, Corrientes \\ ARGENTINA}

Email: carolina@vet.unne.edu.ar

Recibido : 25-04-2012

Aceptado: 30-08-2012 